\title{
Assessment of left and right ventricular volumes and function with treadmill exercise stress cardiovascular magnetic resonance
}

\author{
Leah Geyer, Subha V Raman, Vijay Balasubramanian, Beth McCarfthy, Orlando P Simonetti, Stephen C Cook \\ From 2011 SCMR/Euro CMR Joint Scientific Sessions \\ Nice, France. 3-6 February 2011
}

\begin{abstract}
Introduction
Pharmacologic stress testing with cardiovascular magnetic resonance (CMR) is employed to assess cardiac function and perfusion in various conditions. However, the response elicited may not compare to that obtained during physical exercise. Advances in CMR technology now include a MR-compatible treadmill proven feasible in evaluation of ischemic heart disease.
\end{abstract}

\section{Purpose}

The aims of this study were: (1) compare biventricular volumes and function obtained with gated and real-time imaging techniques at rest and (2) biventricular volumes and function measured after peak treadmill exercise stress CMR in healthy volunteers.

\section{Methods}

Ten young adults (mean age $26.1 \pm 8.4$ years); seven men, were prospectively enrolled. All examinations were performed with a $1.5 \mathrm{~T}$ scanner (Siemens Avanto) and 32-channel phased array coil (Rapid MRI, Columbus). Ventricular volumes were obtained at rest with gated (SSFP) and real-time imaging (TSENSE). Nine to 10 contiguous short axis and axial slices provided coverage of left and right ventricular volumes respectively. Endocardial borders were manually segmented and ejection fraction (EF) calculated as the difference between enddiastolic volume (EDV) and end-systolic volume (ESV) divided by EDV. Segmented breath-hold Cine SSFP imaging was performed at rest (TE $1.0 \mathrm{~ms}$; TR $3 \mathrm{~ms}$; temporal resolution $39 \mathrm{~ms}$; flip angle (FA) $69^{\circ}$, bandwith (BW) $930 \mathrm{~Hz} /$ pixel and slice thickness $8 \mathrm{~mm}$ ). Non-triggered real-time TSENSE image acquisition was

The Ohio State University, Columbus, OH, USA performed at rest and stress (TE $1.0 \mathrm{msec}$; TR $2.3 \mathrm{msec}$; temporal resolution $46 \mathrm{~ms}$, FA $62^{\circ}, \mathrm{BW} 1360 \mathrm{~Hz} / \mathrm{pixel}$ and slice thickness $8 \mathrm{~mm}$ ). Patients underwent treadmill exercise CMR with 12-lead ECG system (Cardiosoft, $\mathrm{GE})$ to achieve a goal of $\geq 85 \%$ age-predicted maximum heart rate (APMHR). Real-time imaging was performed immediately upon cessation of exercise.

\section{Results}

All 10 young adults successfully completed the treadmill exercise CMR examination, achieving a maximal heart rate $186.9 \pm 11.1 \mathrm{bpm}(96.5 \pm 5.7 \%$ APMHR $)$. From the end of exercise to the start of imaging, on average $20.5 \pm$ $4.1 \mathrm{~s}$ elapsed. Results of left and right ventricular volumes and function obtained with SSFP and TSENSE techniques at rest and stress are listed in Table 1. ECG data revealed no arrhythmias or ST segment changes during exercise.

\section{Conclusions}

In-room treadmill exercise stress CMR provides a novel and feasible technique to assess right and left ventricular function. This study not only demonstrates the

Table 1 Ventricular Volumes and Function Obtained at Rest and Stress Measured by Segmented and Real-Time Seq

\begin{tabular}{llll}
\hline & $\begin{array}{l}\text { End Diastolic } \\
\text { Volume }(\mathbf{m L})\end{array}$ & $\begin{array}{l}\text { End Systolic } \\
\text { Volume }(\mathbf{m L})\end{array}$ & $\begin{array}{l}\text { Ejection } \\
\text { Fraction (\%) }\end{array}$ \\
\hline SSFP Rest RV & 117.4 & 56.3 & 52 \\
TSENSE Rest RV & 133.1 & 55.5 & 58.4 \\
TSENSE Stress RV & 99.2 & 30.9 & 68.7 \\
SSFP Rest LV & 136.3 & 57.6 & 57.6 \\
TSENSE Rest LV & 126.0 & 52.6 & 58.2 \\
TSENSE StresS LV & 125.3 & 30.1 & 76 \\
\hline
\end{tabular}


equivalence of real-time and segmented techniques, but also provides the framework to measure function at peak exercise stress. Importantly, this study describes the biventricular response to treadmill exercise in healthy volunteers.

Published: 2 February 2011

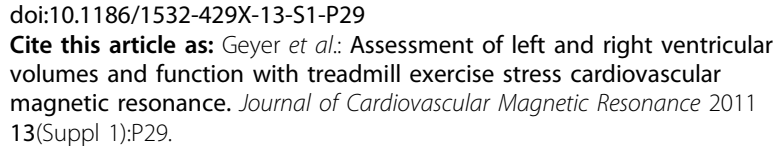

Submit your next manuscript to BioMed Central and take full advantage of:

- Convenient online submission

- Thorough peer review

- No space constraints or color figure charges

- Immediate publication on acceptance

- Inclusion in PubMed, CAS, Scopus and Google Scholar

- Research which is freely available for redistribution 